\title{
To the conservation of biodiversity of North Ossetia: an environmental and political aspect
}

\author{
B.G. Koibaev*, S.F. Lamarton \\ North-Ossetian State University, 44-46 Vatutina str., 362025, Vladikavkaz, Russia
}

\begin{abstract}
This work shows that one of the main indicators of the ecological component of the modern process leading to the destruction of the biodiversity of the main faunistic complexes is a barbaric attitude towards limited natural resources. The main attention is paid to the legal mechanism for controlling the purposeful extermination of the animal world, pollution of the water basin, which will stabilize the state of ecosystems that are extremely important for the life support of the population (water and terrestrial biological resources). It is concluded that the current situation requires the creation of regulatory state mechanisms to ensure the environmental and national security of the republic and the entire Central Caucasus, as a unique natural region. The ecological function of the state as a guarantor of ecological safety and as a part of the national security system has been substantiated.
\end{abstract}

\section{Introduction}

Today, one of the most important problems of human existence is the preservation of the biological diversity of the planet Earth - this is the most important strategic task of the world community, and first of all scientists and government leaders who are invested with knowledge and power. The obtained data on the faunistic, chorological and biogeographic features, the historical pathways of the formation of the diversity of model groups within the studied region are important for understanding the formation of large biogeographic centers of the Caucasus in the formation of the diversity of the main faunistic complexes.

It is well known that biological diversity ensures the stability of ecosystems, therefore, power structures, both regional and federal, and global political forces, which must clearly understand and with full responsibility approach the solution of this problem, play an important role in maintaining this stability, from which the existence of all mankind depends.

Currently, a threat to the stability of natural ecosystems is anthropogenic activity, which introduces significant changes in the environment (a sharp change in climatic conditions, shallowing and pollution of rivers, etc.), all this leads to a violation of natural natural cycles, and ultimately leads to to the impoverishment of biodiversity, and a decrease in the vital conditions for the existence of mankind, not only in one particular region, but also on the entire planet.

In this regard, the research topic we have chosen is quite relevant.

The purpose of the work is to determine a strategy for the preservation of the main natural faunistic complexes, as the basis for the biodiversity of the Central Caucasus.

\footnotetext{
${ }^{*}$ Corresponding author: koibaevbg@mail.ru
} 
The geological history of the Caucasus is very original and complex and in many ways influenced the formation of a variety of natural conditions in the region, its climate, and soils. In turn, these unique conditions determined the uniqueness of the faunistic diversity of natural ecosystems.

In its geographical position, the republic lies in the development zone of the subtropical climate, but it is separated from the southern regions by powerful mountain ranges and is significantly open to the north. In this regard, the temperate continental climate prevails, in the plain zone - arid. In recent years, the winter season is short, the temperature is above zero, the summer becomes hot. Summer temperatures are $19-350 \mathrm{C} \mathrm{C}$, in winter $-7-+20 \mathrm{C}$.

The duration of sunshine throughout the year can be considered an important indicator for the climate of the Republic of North Ossetia-Alania. In the mountainous zone of the republic, this figure ranges from 1980 to 2780 hours. Switzerland, Austria, Italy have similar indicators.

The number of snowy days in the gorges (Tseyskoye, Digorskoye, Zakinskoye, Mamison, Uallagkomskoye) is 105-140 days, the snow cover reaches 50-60-140 cm.

Tseyskoye gorge is one of the most picturesque gorges in North Ossetia. The total land area of the Tseysky district is about 6 thousand hectares, of which $62 \%$ are located in a highmountainous hard-to-reach zone, which ensures an equilibrium state of natural ecosystems.

All of these features have an impact on the formation of the faunistic complex of the region.

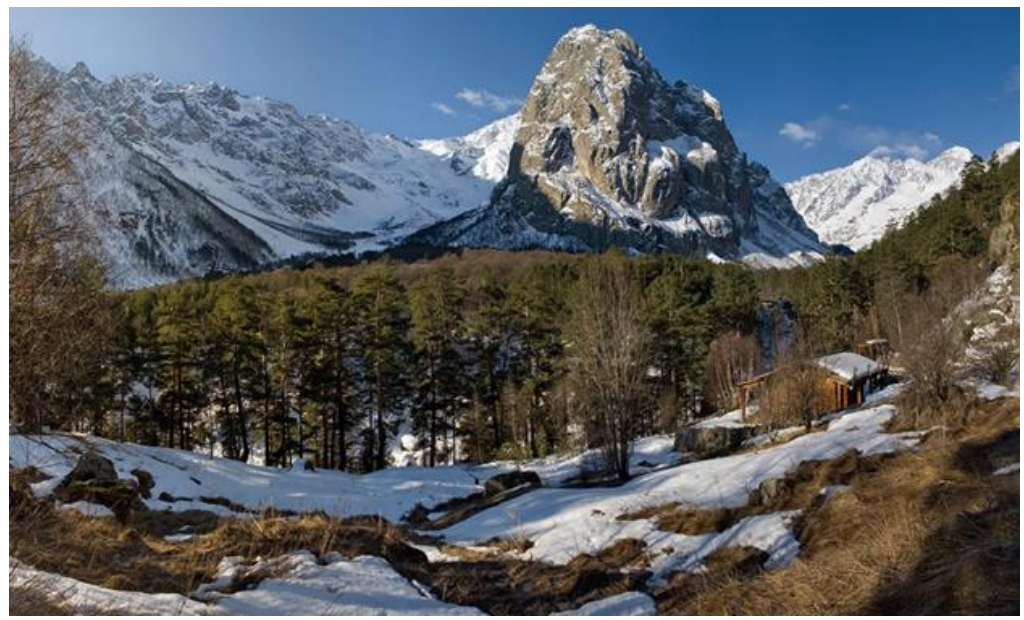

Fig. 1. Tseyskoye gorge

\section{Material and method of study}

The material is presented by the stock collections of the Zoological Museum and the Department of Zoology and Bioecology of NOSU, as well as by his own collections received by the author during field expeditions in 2016-2020 [1,2,3]. The material was collected according to generally accepted methods. The analysis of the regulatory and legal framework of the republic from 2007 to the present was carried out, as well as the data of sociological surveys of the population $[4,5,6,7]$. 


\section{Results and discussion.}

Despite the fact that individual landscape zones, including the animal world, are an integral ecological and faunal complex, any change in environmental factors leads to a change in the structure of the complex, which leads to the formation of various biocenotic communities within a particular natural zone, which, in addition to systematic differences, imply a different level of their use as bioresources.

The most obvious changes under the influence of environmental factors (including anthropogenic) are traced by the example of communities of aquatic invertebrates. Any interference with the natural environment entails irreparable changes in the structure of faunal complexes (mechanical sampling of river gravel is a seemingly harmless necessity, but in this case the substrate of many litoreophilic species, including larvae of amphibiotic species, often endemic to the Caucasus region, is destroyed). Only on the rivers of the Ardon basin, we had to observe unauthorized dumping of housing and communal services waste into the water (the villages of Mizur, Galon, Sadon), along the slopes surrounding the Ardon River, picturesque garbage dumps for $200-500 \mathrm{~m}$. The Ardon River itself, the area between the settlements of Unal and Zintsar (the vicinity of the Unal tailings storage facility) is devoid of representatives of amphibious fauna, because in this area, through cracks in the concrete bowl of the tailings storage facility, waste from the lead-zinc production of the Mizur processing plant seeps into the water, so insects do not develop in this area. Even if there are isolated representatives of the fauna, they are carried into the Ardon River from tributary streams (for example, the Unaldon River).

The quantitative composition of benthos is also affected by the construction work of the next cascades of the Zaramagskaya HPP, which pass upstream of the Ardon River - one of the unfavorable sections is considered to be a segment of the Badka River, a small mountain river, with a length of $14 \mathrm{~km}$. The sources of the river are located at an altitude of $4125 \mathrm{~m}$. The river is an excellent refuge for amphibious litoreophilic fauna (rocky bottom, rapids, where the speed reaches $1.5-2 \mathrm{~m} / \mathrm{sec}$., temperature-100C). Here live vesnyanki, caddisflies, mayflies, the population density of the river bottom for vesnyanki is $7 \mathrm{ex} . / \mathrm{m} 2$, caddisflies $80 \mathrm{ex} . / \mathrm{m} 2$, mayflies - $67 \mathrm{ex} . / \mathrm{m} 2$, diptera - $30 \mathrm{ex} . / \mathrm{m} 2$. However, after construction work (a tray for water discharge from hydroelectric power plants) - a section of the river, about 200 $\mathrm{m}$ long, remained, according to A. K. Bekoev [8], lifeless, moreover, the migration of fauna from Baddon to Ardon and from the river Ardon to Baddon - completely excluded due to an artificial concrete obstacle, which completely excludes the existence of fauna and its migration on this segment. And there are countless such unfavorable segments in the basin not only on the Ardon River, but also on all the rivers of the republic. It is not necessary to go far for an example, within the city of Vladikavkaz, such a "visual aid" of the problems of the water basin of the republic is the Terek River. The fauna of oxyphilic amphibious insects, as well as the ichthyofauna, has been completely destroyed during the entire passage of the Terek River on the segment: Vladikavkaz-Alkhanchurt - Beslan and further, with minor islands of life in some areas where the anthropogenic factor is reduced (within the limits of the locality). Nogir-marked imago of Rh. nubila caddisflies). In general, comparing the population data, we can talk about a tenfold reduction in the density of benthos, up to the complete disappearance in some segments of the largest watercourse of the republic.

The fauna of terrestrial and aquatic invertebrates is the most diverse (the reserve is home to about 400 species of butterflies, there is still no complete information on the fauna of Coleoptera, Hemiptera and Diptera). Currently, the amphibiotic fauna of protected areas has been studied in some detail. According to A. K. Bekoev (Bekoev, 2019), the reserve is home to more than 174 species of amphibiotic insects from the orders caddisflies, freckles, mayflies, etc. 
A number of representatives of entomofauna, both terrestrial and aquatic, are included or recommended for inclusion in the Red Books of the republic and Russia: Lepidoptera Papilio machaon, Parnassius apollo, Iphiclides podalirius, Parnassius mnemosyne; hawk moth family (Acherontia atropos); order Coleoptera: Caucasian ground beetle (Carabus caucasicus), Hungarian ground beetle (Carabus hungaricus), odorous beauty (Calosoma sycophanta); stoneflies - Filchneria balcarica. Based on the materials of the Red Book of North Ossetia (Red Book of the RSO-Alania, 2002): 1 species of Cyclostomata, 3 species of fish, 3 species of amphibians, more than 30 species of birds, 45 species of insects, 9 species of reptiles, 15 species of mammals.

The ratio of the listed faunal groups of animals is shown in the diagram (Fig. 2).

To date, we do not have accurate data on the species composition of the main representatives of the animal world (both vertebrates and invertebrates) included in the Red Book of the republic, this work is only carried out by relevant specialists.

We can only state the fact that in the course of the work, we have identified a negative impact on the communities of amphibious fauna on almost all rivers of the republic, with the exception of segments in the upper reaches of the main basins, where the density and species composition of the fauna indicate the well-being of the habitat (the density of benthos reaches 1000 eq. $/ \mathrm{m} 2$, the species composition of faunal complexes, in particular, communities of zoobenthos, is also quite diverse (the presence of 6 families of stoneflies, 3 families of mayflies, 6 families of caddisflies, 7 families of dipteran).

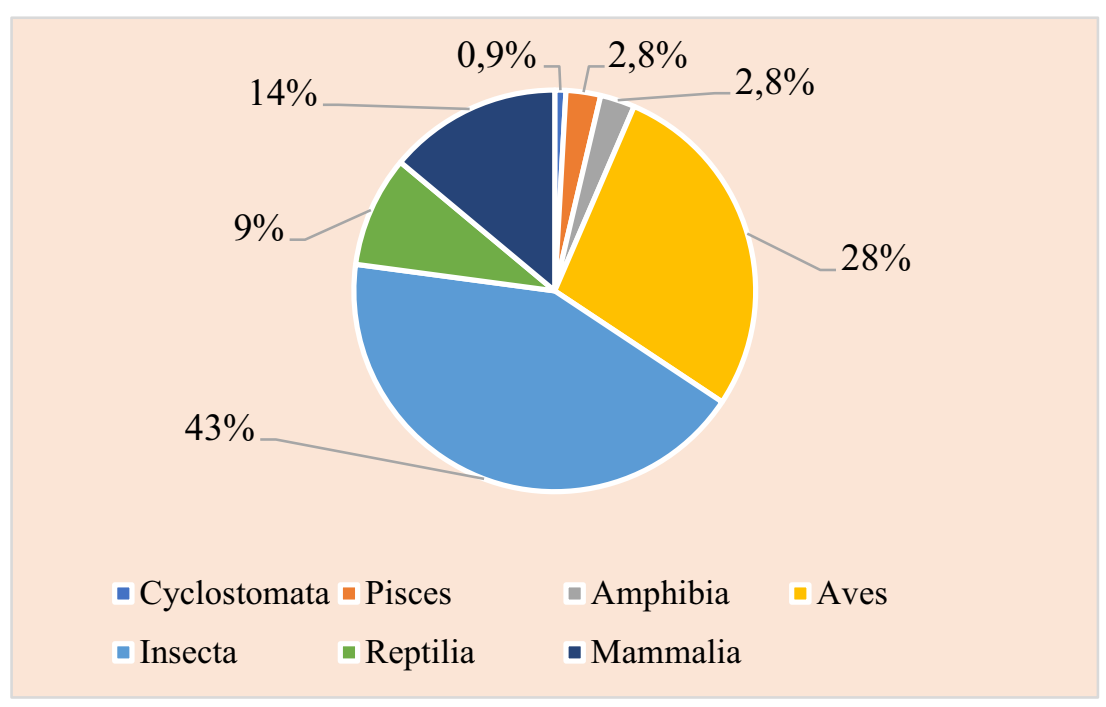

Fig.2. The ratio of faunal groups of animals in the North Ossetian Reserve (Red Book, 2002).

These facts indicate the need for environmental monitoring on the territory of the republic. Therefore, the conservation of biodiversity is not just a new direction of nature protection, it is an integral part of the concept of the transition of humanity to the principles of sustainable development.

Therefore, the issues of wildlife protection are not a narrow task of humanity and at the same time a condition for its survival on the planet. This implies that in order to preserve life on the planet, it is necessary not only and perhaps even not so much to conduct traditional environmental work, but also to rebuild the economy and social system accordingly in order to harmonize the relationships of all three main blocks of the planet-nature, society and economy.

For many years, the illegal extraction of commercial, rare and endangered aquatic biological resources, as well as valuable species of animals, birds, reptiles, and the main food 
base of the ichthyofauna - amphibiotic and aquatic insects that cannot exist in polluted reservoirs-has been under the strict control of state bodies (the Ministry of Natural Resources) in the North Caucasus.

In addition to biomonitoring the state of surface waters, every year, in order to preserve water bioresources and stabilize the situation, operational and preventive measures of "Putin"are carried out. All divisions of the fish hunting inspectorate take part in the events. Operational search groups are being created on coastal territories and highways. At the traffic police posts, vehicle checks are carried out, the employees of the traffic police department inspect passengers at stations and train stations.

Therefore, it can be argued that the main reason for the depletion of aquatic biological resources is the imperfection of the regulatory legal framework in the field of fisheries and conservation of aquatic biological resources in terms of timely approval of the total allowable catches and the distribution of quotas for the catch (production) of aquatic biological resources for coastal fisheries, the organization of monitoring compliance with legislation and the organization of state protection of aquatic biological resources, as well as the organization of conducting and financing scientific research to ensure the conservation of aquatic biological resources and their distribution.

The regional authorities are working to include in the national project "Ecology" a new federal project "Rehabilitation of the Terek River Basin". This is due to the high pollution with untreated wastewater, as well as the absence of fish channels at the three dams of the Terek River.

\section{Conclusion}

Thus, based on the above, among the environmental threats to the region should be identified: decline in biodiversity; destruction of mountain forests; depletion of water resources; the consequences of industrial pollution; degradation of agricultural lands; often, violation of the PA system; seizure of the coast; deterioration of the ecological situation in cities; sprawl of landfills.

To ensure the environmentally sustainable development of the North Caucasus, a new environmental policy is needed that would contribute to the socio-economic development of the region. And the leading role in the development of such a strategy belongs to the State.

\section{References}

1. B. G. Koibayev, M. A. Mukagov, S.K. Cherchesova, XX International Scientific and Practical Conference, 2, 193-199 (RUDN, Moscow, 2019)

2. I.E. Dzhioeva, M.A. Mukagov, B.G. Koibayev, O.R. Bzykov, VII All-Russian (with international participation) scientific symposium on amphibiotic and aquatic insects, 35-40 (NOSU, Vladikavkaz, 2019)

3. B. G. Koibayev, M. A. Makarov, Actual problems of chemistry, biology and biotechnology: XI All-Russian Scientific Conference, 154-158 (NOSU, Vladikavkaz, 2017)

4. Decree of the Government of the Republic of North Ossetia-Alania of 23.03.2012 № 84 "On republican target programs in the field of nature management and environmental protection for 2012-2014". (Vladikavkaz, 2012).

5. State Program "Environmental protection, ecological safety and well-being of the Republic of North Ossetia-Alania" for 2014 - 2020: docs.cntd.ru >document / 460207683 
6. F.B. Tsogoeva, Ecological safety of mountainous territories of the Republic of North Ossetia-Alania: socio-cultural aspect (North Ossetian Inst. of Humanitarian and Social Research, Vladikavkaz, 2007)

7. B.G. Koibaev, X-th All-Russian scientific conference "Actual problems of chemistry, biology and biotechnology, 397n (Vladikavkaz, 2016).

8. A.K. Bekoev, S.K. Cherchesova, B.G. Koibaev, M.A. Mukagov, EEC-EM - Eco. Env. \& Cons., 25 (1), 407-410 (2019) 